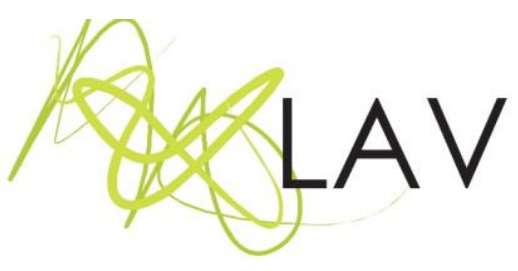

\title{
Geografias em deriva
}

Drifting geographies

\author{
Camila Barbosai \\ Universidade do Estado de Santa Catarina \\ Ana Maria Hoepers Preveii \\ Universidade do Estado de Santa Catarina
}

\section{Resumo}

Caminhar e escrever é diferente de voar e ler. A lembrança nos trouxe assim uma frase de Walter Benjamin, enquanto pensávamos em tudo que já havíamos vivenciado até aqui. Reiniciamos as atividades do ano de 2017, no Hospital de Custódia e Tratamento Psiquiátrico de Florianópolis (HCTP), pensando sobre caminhar e escrever, sobre o contato com o mundo através de uma experiência que envolve, necessariamente, uma superfície, um chão, um território. A proposta deste texto é apresentar as derivas do trabalho realizado no HCTP com os internos através das práticas desenvolvidas nas oficinas "Geografias em Deriva" vinculado ao trabalho anteriormente realizado por uma de nós intitulado Mapas, prisão e fugas: cartografias intensivas em educação.

Palavras-chave: geografias em deriva, oficinas como outros territórios em educação, educação como invenção.

\begin{abstract}
Walking and writing is different from flying and reading. The memory brought us, then, a phrase from Walter Benjamin, while we thought about everything that we had already experienced so far. We reopened the activities of year 2017, at the Hospital of Custody and Psychiatric Treatment (Hospital de Custódia e Tratamento Psiquiátrico - HCTP), in Florianópolis, thinking about walking and writing, about the contact with the world through an experience that necessarily involves a surface, a ground, a territory. The purpose of this text is to present the drifts of the work carried out at HCTP with inpatients through practices developed in workshops called "Drifting Geographies", linked to the previous work developed by one of us, entitled Maps, prison and flight: intensive cartography in education.
\end{abstract}

Keywords: drifting geographies, workshops as other territories in education, education as invention.

Não basta que tudo comece, é preciso que tudo se repita, uma vez encerrado o ciclo das combinações possíveis.

[Gilles Deleuze, 2006, p. 22]

Repetir, repetir - até ficar diferente.

[Manoel de Barros, 1994, p. 12]

Revista Digital do LAV - Santa Maria - vol. 10, n. 3 p. 17-30 - set./dez. 2017 ISSN 1983 - 7348

http://dx.doi.org/10.5902/1983734830392 


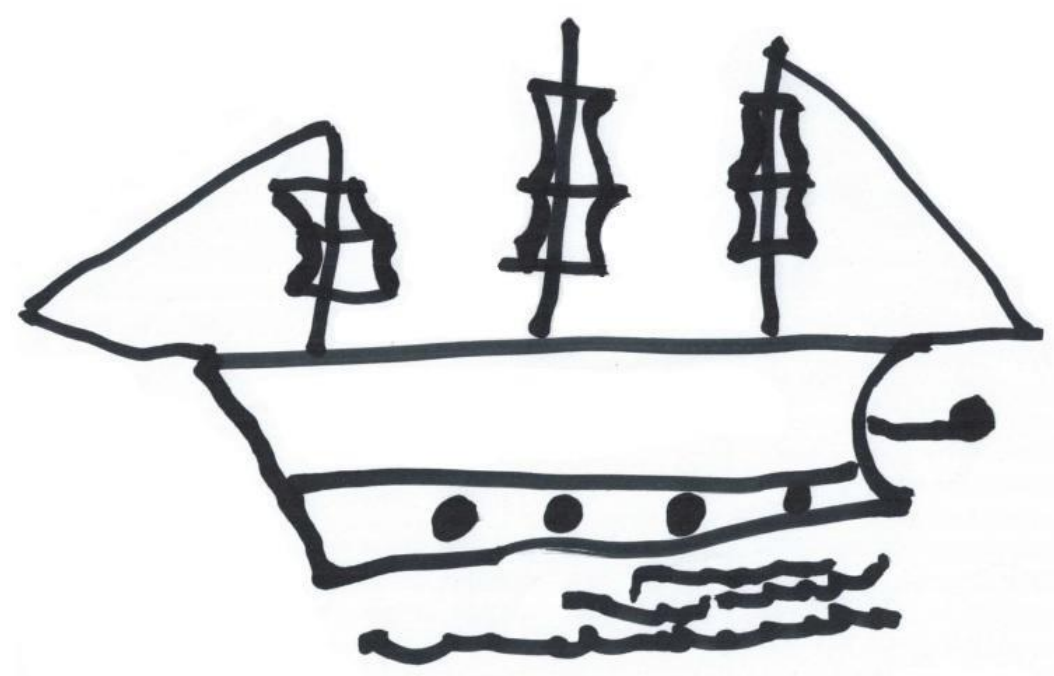

Figura.01: Desenho criado por um dos internos do HCTP nas oficinas realizadas. Fonte: Arquivo pessoal.

Caminhar e escrever é diferente de voar e ler. A lembrança nos trouxe assim uma frase de Walter Benjamin, enquanto pensávamos em tudo que já havíamos vivenciado até aqui. Novamente, ao ler o texto "E-ducando o Olhar: a necessidade de uma pedagogia pobre", de Jan Masschelein, a frase voltou a provocar. Reiniciamos as atividades do ano de 2017, no Hospital de Custódia e Tratamento Psiquiátrico de Florianópolis (HCTP) ${ }^{1}$, pensando sobre caminhar e escrever, sobre o contato com o mundo através de uma experiência que envolve, necessariamente, uma superfície, um chão, um território.

\footnotetext{
${ }^{1}$ O Hospital de Custódia e Tratamento Psiquiátrico (HCTP) ocupa um lugar diferenciado no sistema prisional, posto que, na geografia das instituições disciplinares, ele se instala nas fronteiras de pelo menos três instituições: a prisão, o manicômio e o hospital. Situado dentro de um complexo penitenciário e administrado pelo Departamento de Administração Prisional (DEAP), o HCTP encerra sujeitos cujos crimes são inimputáveis dada a constatação de algum "transtorno mental". Assim, a constituição prevê a tais sujeitos não a aplicação de uma pena, mas de uma "medida de segurança". Esta medida de segurança consiste em uma espécie de tratamento psiquiátrico (no qual se fundem saberes médicos e psicológicos) que visa garantir o bem-estar e a segurança da sociedade e do sujeito. Algo de prisão, de hospital e de manicômio, porém nenhum deles exatamente e um pouco disso tudo. (PREVE, 2010).
}

Revista Digital do LAV - Santa Maria - vol. 10, n. 3, p. 17-30 - set./dez. 2017 ISSN 1983 - 7348 http://dx.doi.org/10.5902/1983734830392 
No primeiro encontro ${ }^{2}$, depois que assistimos ao filme Andarilho, de Cao Guimarães ${ }^{3}$, ficamos pensando sobre o que nos passa quando experimentamos o que está no caminho enquanto o atravessamos. Diferente de voar e ler - em que sobrevoamos caminhos distantes de nós mesmos e que nos permitem imaginar e ir além do que é palpável -, quando caminhamos (e escrevemos) temos uma nova possibilidade de existir através do contato com outros elementos que participam da realidade concreta que nos cerca, pois caminhar e escrever é estar diante das forças que dão concretude a este mundo, o mundo material. Você pisa em um chão de terra, lajota, cimento, cerâmica, grama; em qualquer lugar onde esteja, há uma superfície que te sustenta e, por isso, age sobre você de alguma maneira. Uma paisagem sempre será percebida diferentemente entre os seres humanos, mesmo que alguns olhares se cruzem. Aos seus próprios olhos, cores vibram e formam uma mistura de elementos. Aos que não enxergam com os olhos, a visão é aberta de outra maneira; o tato, o olfato, o paladar e a audição são estimulados em outras proporções; e os que veêm com os olhos são, muitas vezes, "cegados" pelo excesso de imagens neste mundo $24 / 7^{4}$, de maneira que nem sempre percebemos o que nos cerca: não dá tempo de... passou.

Chegamos para o encontro da segunda oficina com aquela frase de Benjamin ainda ressoando na cabeça. Preparamos o plano de oficina no instante em que esta frase provocava a pensar. Nossas mentes pulsavam. Há experiências que nos marcam de tal forma que incorporamos a proposta dada e a desdobramos em nossa própria vida posteriormente. Esse foi um começo, sem planos futuros. Um dispositivo. Assim como o título que sustenta a atividade, não estava em jogo o fim como objetivo, um lugar que já se enxerga no momento mesmo em que se propõe a dar o primeiro passo no caminho. Não. As derivas se propõem a começar algum movimento. Não há planos certos quando se provoca o pensamento do outro. Pensar é então como derivar no caminho. O caminho é aquilo que te agonia, que te provoca e faz surgir algo novo. Já a deriva é a experiência em si, o desvio do caminho, da rota do barco quando tomado por um vento forte. Nesse sentido, o plano de oficina é como se fosse a vela do barco, pois é necessário algo sólido que possa sustentar a energia provocada quando se põe a navegar. E o que você propõe - no exercício da oficina - diz sobre o que você procura. Ali, naquele momento, procurávamos os movimentos possíveis dos "meninos" dentro daquele Hospital de Custódia. As grades e cubículos nos abalaram de tal maneira que, muitas vezes, não

\footnotetext{
2 O primeiro encontro aqui se refere a um novo começo. Estamos no HCTP desde 2005 com algum tipo de projeto de extensão e/ou de pesquisa. Neste caso, um projeto de ensino reiniciando com outros materiais e uma ideia nova.

${ }^{3}$ Andarilho é um filme sobre a relação entre o caminhar e o pensar, dirigido por Cao Guimarães e lançado em 2006, no Brasil.

4 O termo "24/7" alude ao ritmo de vida moderno no qual estamos em função do sistema 24 horas por dia, 7 dias por semana. Tema central do livro Capitalismo tardio e os fins do sono, de Jonathan Crary.
}

Revista Digital do LAV - Santa Maria - vol. 10, n. 3, p. 17-30 - set./dez. 2017 ISSN 1983 - 7348 http://dx.doi.org/10.5902/1983734830392 
conseguíamos ficar tranquilas quando voltávamos para casa e lembrávamos que havia pessoas ali dentro, trancadas em espaços extremamente reduzidos quando comparados com os que temos acesso. Constituído por grades, muros, portões de ferro, cadeados, corredores, vigilância, privação de movimentos... trata-se de um espaço normativo, assim como outros em nossa sociedade. E é preciso reconhecer a maneira como os elementos que constituem este espaço atrofiam as possibilidades de movimento de corpo e pensamento, mas também é preciso perceber que há movimento, por menor que seja, e que ele pode nos levar muito além, mesmo quando se está cercado por grades; que a deriva é possível ali onde só parece haver o caminho da norma.

A proposta deste texto é apresentar as derivas do trabalho realizado no HCTP com os internos através das práticas desenvolvidas nas oficinas "Geografias em Deriva" vinculado ao trabalho anteriormente realizado por uma de nós intitulado Mapas, prisão e fugas: cartografias intensivas em educação ${ }^{5}$ - e, portanto, fazer a Geografia derivar.

\section{Deriva I}

Hoje foi um daqueles dias em que sentimos a felicidade de seguir, mesmo com as dores (físicas e emocionais), aquilo com que nos comprometemos: viver cada oficina aberta à experiência única que é este encontro. $E$, uma de nós, assim estava: "Não acordei me sentindo bem. Pensei em não ir para o HCTP. Por um momento, a cama parecia ser o melhor abrigo para mim... mas tenho estado com tanta energia de viver - tentando sair da minha zona de conforto - que bastou a voz da minha mãe ecoar, como um despertador de vida (ou de sonho) para eu me levantar: Não deixa a dor tomar conta de

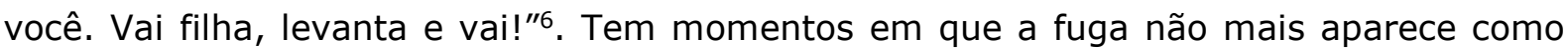
abertura no caminho para outras possibilidades de existência, mas muito mais próxima do abismo que é encarar quem somos. Decidida, ela foi. E porque há todo tipo de fuga, importa não fugir daquilo que nos damos, e afirmar aí a liberdade de existir. Sem desculpas para os medos de enfrentar um novo desafio. Sem culpas.

Esses chamados, que parecem não ter a ver com a pesquisa, são como as linhas que esticamos na oficina, para sustentar um plano de acontecimentos. Na bagagem, levávamos muitos pesos necessários: computador, três estojos com materiais para escrever, papéis, caixa de som e o peso mais intenso de todos, a honestidade. Aquela que nos é necessária em todos os momentos da vida; na alegria, na tristeza, na preguiça

\footnotetext{
${ }^{5}$ Para saber mais ver Preve (2010).

${ }^{6}$ Extraído do nosso caderno de campo. Todas as vezes que aparecer algo entre aspas no corpo do texto, elas se referem as nossas anotações no caderno de campo.
}

Revista Digital do LAV - Santa Maria - vol. 10, n. 3, p. 17-30 - set./dez. 2017 ISSN 1983 - 7348 http://dx.doi.org/10.5902/1983734830392 
ou no mistério da existência: a honestidade é o chão que sustenta nossas ações e pensamentos; a todo o momento ela testa nossos passos no caminhar de ser quem somos. É assim que vamos rabiscando neste papel uma experiência. Chegamos muito atrasadas, cerca de 50 minutos depois do horário de início das oficinas. Ao chegar no HCTP, tínhamos que nos virar com o tempo que restava e, no começo, um pouco atordoadas em organizar os materiais, percebemos que tudo o que nós precisávamos era respirar, reencontrar a força que nos punha ali, que nos move na vida. Paramos. Recomeçamos. Sentamos no banco próximo de uma das mesas e pedimos a eles que se aproximassem para podermos nos escutar. Como sempre, levamos outros elementos para lá, na intenção de envolver todos que escolheram estar presentes no encontro. A música foi o elemento de hoje para alguns movimentos. Posicionamos a caixa de som perto daqueles que estavam afastados - porém com atenção e presença - e demos o play no computador que estava ao lado. É nesses momentos que a tecnologia se torna uma aliada forte da prática educativa; utilizar os recursos tecnológicos para contemplar o máximo de pessoas que conseguir é um exercício a se aprender constantemente.

Aos meninos que estavam mais atentos ao que falávamos, pedimos sugestões de filmes para o novo projeto com cinema. Recentemente, a sala de vídeo do HCTP ficou pronta, e eles estavam ansiosos para poder usufruir deste espaço. Precisamos da força da vontade deles para continuar. O desejo necessita ser compartilhado para ganhar consistência. Começamos juntos a oficina, pois, aqui, nunca fazemos algo sozinhas, é com eles - e também com a força de outras parceiras de caminhada - que conseguimos guiar os encontros. A lista de filmes cresceu rapidamente - e, neste momento, desejos presos, confinados, afloraram - e logo escutamos outra voz. Era um dos meninos dizendo: "Tá bom, tá bom. Já tem filme pra caramba aí". Neste momento, eles nos guiavam. Tínhamos pouco tempo e já era hora de partirmos para a proposta de atividade do dia: continuar o exercício de descarregar, numa folha de papel, as palavras que pesam na bagagem da história de vida de cada um.

\section{Deriva II}

Caio $^{7}$ foi chamado para falar com o advogado. Apressou o passo, mal sabia o que o esperava. Continuamos a oficina com os outros que estavam ali. Quase todos tinham escrito no papel a palavra que gostariam de esquecer, palavra que no momento não cabia naquele lugar que eles escolheram sonhar.

\footnotetext{
${ }^{7}$ Este nome, assim como o de outros internos, foi inventado e não faz referência a sua identidade original, de maneira a cumprir ordem de sigilo de identificação dos internos do HCTP.
}

Revista Digital do LAV - Santa Maria - vol. 10, n. 3, p. 17-30 - set./dez. 2017 ISSN 1983 - 7348 http://dx.doi.org/10.5902/1983734830392 
Vez ou outra escutávamos o quanto é difícil viver no HCTP. Davi completa a sentença que viveu na pele durante quase 24 anos de reclusão em espaços prisionais: "Nenhum dos lugares que eu passei todos esses anos foram piores do que este".

Começamos a rodada deste novo jogo - é muito bom quando a oficina se desenvolve na prática como um jogo, onde todos têm o seu momento de fala e também de escuta com as palavras que cada um deixa aflorar. Eles não demoram a expressá-las. É como se cada um carregasse a palavra como um fardo na bagagem. Falar, escrever, soa igual como quando nos livramos do peso carregado ao parar de caminhar.

\section{Deriva III}

Eles são tão curiosos que, mal começamos a falar, e já temos várias ideias elaboradas para realizar com os objetos que vemos diante de nós: papel kraft na cor marrom e algumas canetas coloridas, dispostos numa mesa. Nesse momento, temos um possível começo. Apresentamos a eles o que pensamos para este primeiro encontro: "A ideia que trazemos para vocês é a de pensarmos como podemos criar um lugar no qual gostaríamos de viver, habitar, morar". Propomos começar este jogo ${ }^{8}$, de forma que todos participassem. Acionamos o grupo com uma proposta: "Vamos fazer uma brincadeira. Cada um vai ter a sua vez de traçar uma linha neste papel, com uma regra: começar o risco a partir do risco do jogador anterior. Quando eu bater palmas, passem a caneta para o próximo jogador. Vamos fazer isso juntos". Eles toparam. Assim, começamos um jogo de invenções. Imaginávamos as linhas e elas surgiam a cada traço feito no papel, carregadas de afetos, desejos, presença e muita atenção consigo e com o outro. Fizemos duas rodadas nessa primeira proposta e, ao final, tínhamos uma imagem feita por linhas que se cruzavam e se fechavam, sem formar uma figura geométrica nítida: traços livres se interligavam e dividiam a folha marrom e lisa em espaços de tamanhos e cores diferentes; fragmentos do mesmo papel, cada um tinha sua particularidade. Começamos, a partir dali, a explorar outra parte do jogo.

Passaram-se duas rodadas e algumas formas começaram a aparecer no papel, sem compromisso de definirem-se em uma função, colocando-nos diante de um espaço em construção. Assim, prosseguimos o jogo permitindo que formas livres de representação

\footnotetext{
${ }^{8}$ Este exercício é inspirado nas oficinas desenvolvidas no HCTP pela Prof.a Ana Maria H. Preve (2010), presente em sua tese de doutorado Mapas, prisões e fugas.
}

Revista Digital do LAV - Santa Maria - vol. 10, n. 3, p. 17-30 - set./dez. 2017 ISSN 1983 - 7348 http://dx.doi.org/10.5902/1983734830392 
surgissem. Aos poucos, aparecem formas que não seguem a geometria, espaços brotam da tinta da caneta, inscrevem-se no papel marcando-o; cruzam-se linhas.

\section{Deriva IV}

Agora, de outra maneira, já nos sentimos parte do jogo. Além de poder conduzi-lo, somos também conduzidos por ele. Habitamos o espaço construído naquela folha que, no início, era um "nada". Mas, aqui no HCTP, "nada" já é alguma coisa. Recomeçar é um direito. Seguimos agora com outra proposta. Perguntamos a eles: "O que necessitamos construir para habitar este espaço que criamos? O que ainda falta desenhar para que este espaço fique prazeroso para morar?". Um dos internos pede licença para acrescentar algo que, para ele, parece ser fundamental. O traço atravessa de ponta a ponta o papel, e ele segue riscando outra linha, em paralelo. Nasceu um rio... o Rio dos Prazeres.

A nova rodada do jogo empolga a todos, os meninos agora estão livres para escolher o que colocar neste novo lugar; marcar no papel o que para eles, de alguma maneira, é significativo para habitar e conviver nesta nova realidade que - mesmo imaginária começa a provocar-nos uma sensação de pertencimento. O sorriso no rosto e a curiosidade no olhar demonstram isso. Surgem, assim, o Restaurante Bom Gosto, o Hospital HOP, o Cemitério da Saudade, o Clube da Amizade, a Casa de Tratamento de Esgoto, o supermercado e a padaria.

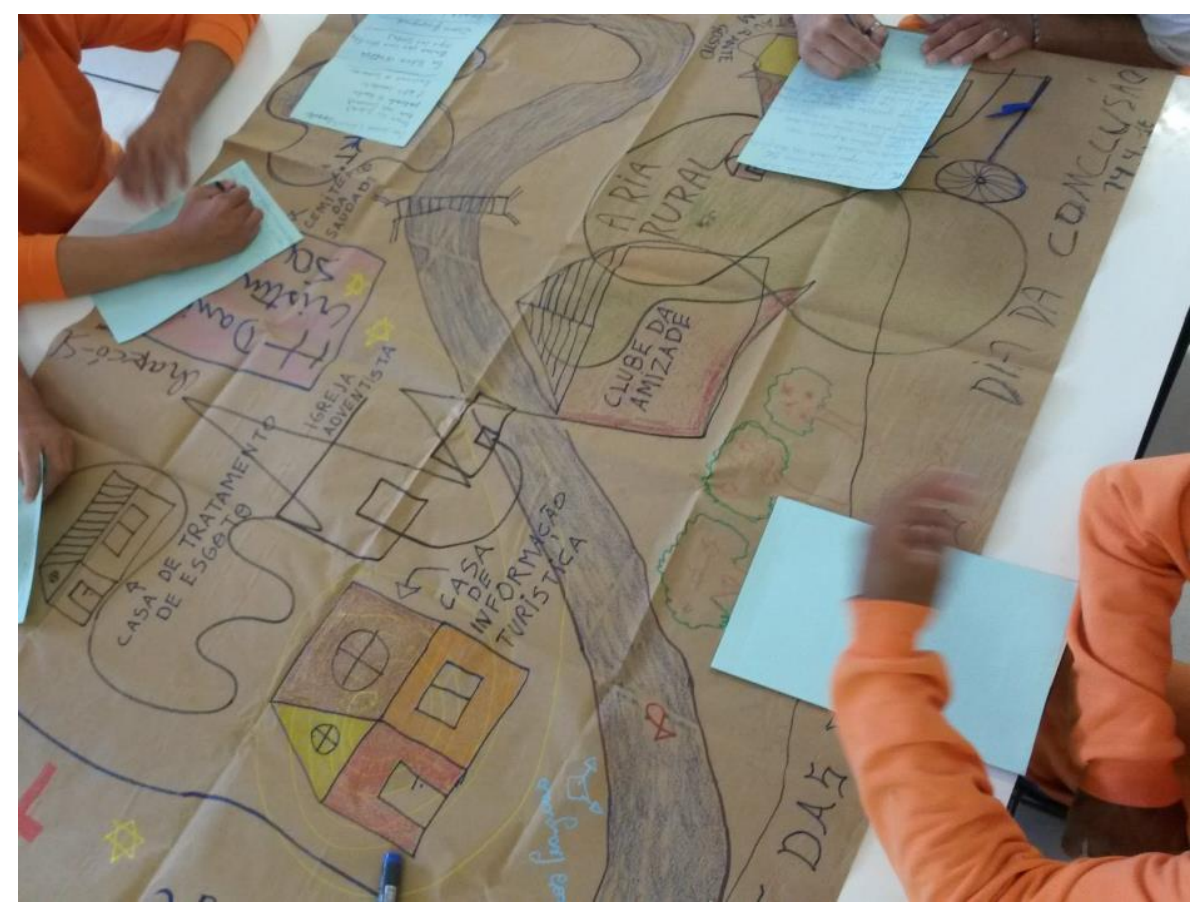

Figura.02: "Vale das Glórias".

Fonte: Arquivo pessoal.

Revista Digital do LAV - Santa Maria - vol. 10, n. 3, p. 17-30 - set./dez. 2017 ISSN 1983 - 7348 http://dx.doi.org/10.5902/1983734830392 


\section{Deriva V}

O ponto de partida das oficinas era justamente quando abríamos aquela folha gigante e, ali, diante de nós, podíamos tocar em algo que construímos juntos. Neste dia, os provocamos a pensar sobre o que já havia sido feito até então. À nossa vista, via-se um rio atravessando o papel de canto a canto - servindo como um divisor de espaços - e uma ponte ligando suas margens. De um lado, temos o Clube da Amizade, a Área Rural e a Casa do Baiano. Algumas árvores também aparecem. Do outro lado, mais preenchido e também mais largo - temos o lago, o Cemitério da Saudade, o Hospital HOP, a estação de tratamento, o mercado; casas e prédios residenciais, e muitas, muitas árvores. Vemos flores em um dos cantos do papel - próximas às residências. Perguntamos sobre como as distribuições de tais lugares está colocada: Por que tantas árvores lá no canto e poucas - e espaçadas - no outro? No primeiro plano, veem-se as casas próximas. 0 segundo parece um plano onde percorremos um espaço "vazio" de um lugar para chegar a outro lugar. O rio liga estes dois cantos. Pronto. Surgiu ali, naquele contexto, um questionamento chave: de onde nascem os rios?

Pedimos a eles que pegassem todos nas pontas do papel e, juntos, movessem em várias direções. Intervimos, pedindo para que parassem o movimento do kraft, quando as árvores próximas às residências - em uma perspectiva 3D - ficam no alto, enquanto as outras - mais espaçadas - ficaram na parte mais próxima do chão, ou seja, na parte mais plana do nosso terreno. Este movimento ajudou-nos a pensar em como responder aos meninos o que é ensinado nas aulas de Geografia na universidade sobre o nascimento dos rios. Eles compreenderam a explicação quando puderam visualizar a ideia do que é a lei da gravidade, segundo a qual (do ponto de vista prático), um objeto tende a cair ao chão quando solto de qualquer parte, pois a massa da Terra exerce uma força de atração sobre a massa dos objetos, conferindo a eles força "peso". Assim, pudemos explicar o que acontecia com os rios: soltamos uma caneta piloto um pouco acima do chão e ela caiu, obviamente. Mas não tão óbvia era uma explicação sobre este fenômeno. Tivemos ajuda de um dos meninos - físico formado, o nosso "cientista" - para retomar a explicação para aqueles que não haviam entendido de primeira. $O$ rio agora não era mais o mesmo, ganhou até um nome: Rio dos Prazeres. É engraçado que as árvores continuam a ser, desde a infância, uma referência para os lugares.

Continuamos a oficina, e é neste segundo momento que nos damos conta de como o que eles desenharam naquele papel se assemelha a uma vila... um vale. Sim, isso! Um vale! $\mathrm{O}$ rio como divisor de águas marcava o lugar que nos remetia às montanhas. Explicamos isso a eles. Pusemo-nos a imaginar de novo. As oficinas são assim, movimentam-se

Revista Digital do LAV - Santa Maria - vol. 10, n. 3, p. 17-30 - set./dez. 2017 ISSN 1983 - 7348 http://dx.doi.org/10.5902/1983734830392 
enquanto estão sendo, nem antes, nem depois; muitas vezes, o que acontece no momento do encontro é a glória pela qual se marca esta pesquisa de educação em geografia. Tal como no trabalho de Preve (2010), o chão tomado pelos pedaços coloridos dos lugares inventados para os deslocamentos, com seus tamanhos variados, feitos ora com tecidos macios, ásperos, lisos, finos, ora transparentes, brilhosos, rugosos se juntam aos outros desenhos e às histórias da Ilha Paraíso do Ciclo9.

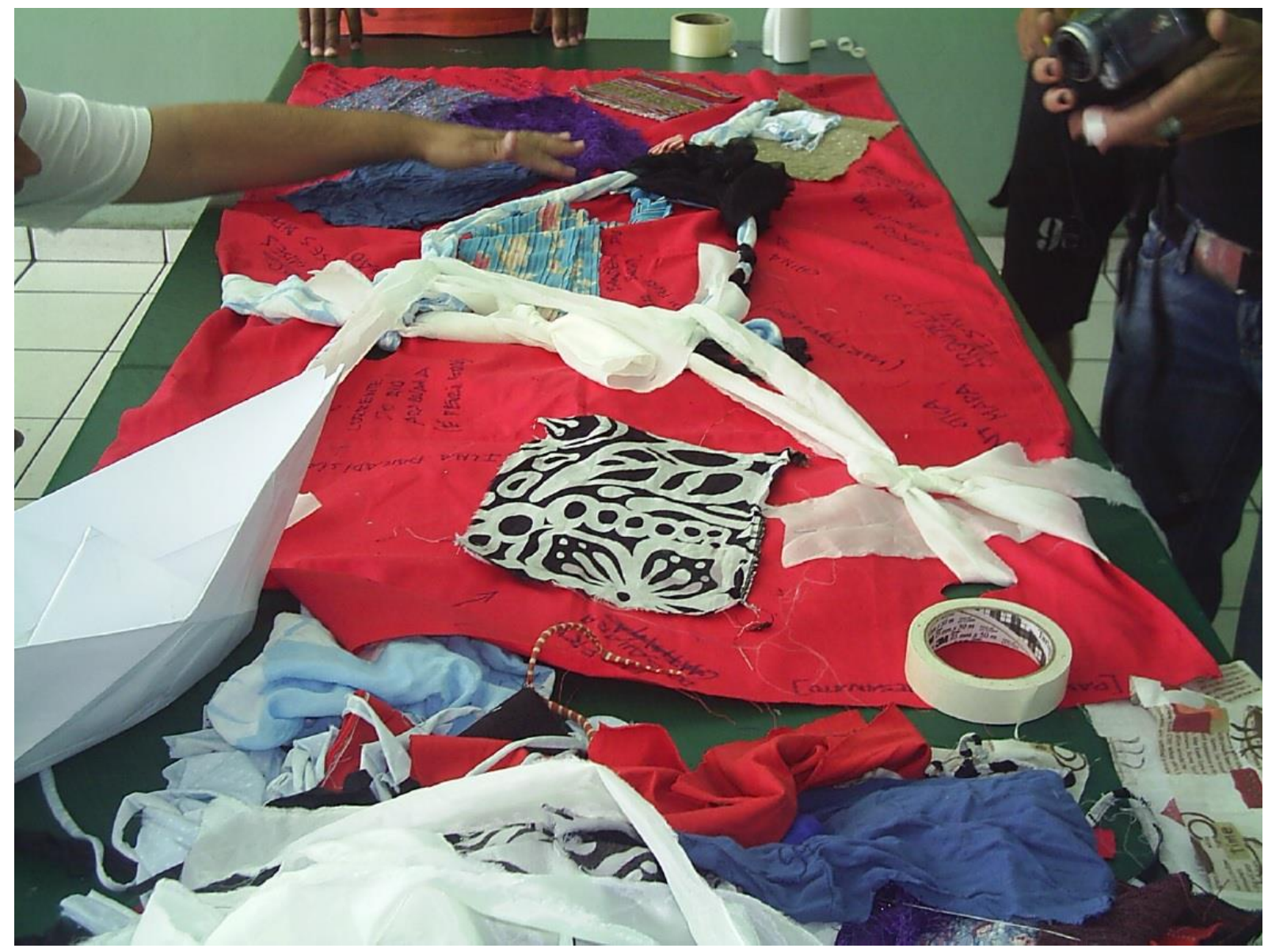

Figura.03: "Ilha Paraíso do Ciclo". Fonte: Preve (2010).

Puro deslocamento dado pelo encontro, composição nova e interessada, cartografia. O Mapa-paisagem já tinha consistência. E a Ilha, deslocando-se, estava cada vez mais longe do continente. Dada à força que tais ilhas e vales adquiriam a cada encontro, afirmamos a possibilidade de engendrar mundos, tirando-nos do torpor cotidiano de alguns modos de habitar trabalhos acadêmicos.

\footnotetext{
${ }^{9}$ Nome dado ao lugar-ilha inventado no trabalho de Preve com desenhos e que para lá nos dirigíamos muitas vezes.
}

Revista Digital do LAV - Santa Maria - vol. 10, n. 3, p. 17-30 - set./dez. 2017 ISSN 1983 - 7348 http://dx.doi.org/10.5902/1983734830392 


\section{Deriva VI}

Passamos os olhos atentamente na folha que outrora não tinha nada inscrito, nenhum rastro dos lugares que vemos hoje ao correr o olhar pelo papel. O tempo passou e, quando nos damos conta, já é hora de terminar o encontro. Recolhemos os materiais enquanto conversamos sobre a atividade que estava sendo feita. Os meninos estão felizes, empolgados, radiantes. Foi a primeira vez que sentimos o elo que construímos com eles durante todos esses encontros. É muito intenso o trabalho que desenvolvemos ali. Nem sempre nossa troca é fácil de ser realizada. Enfrentamos, neste processo de se conhecer e conhecer o outro, vazios que nos fazem parar enquanto caminhamos. É nessas pausas que pensamos sobre o sentido de estar no HCTP, e procuramos um significado para um encontro entre vidas. Há muitas vidas marcadas naquele papel. De fato, "é um mapa de muitos acontecimentos", como ouvimos certa vez ${ }^{10}$.

Um mapa requer um título. Se for para dizer algo sobre alguma "coisa" é preciso - e imprescindível - saber do que se trata a tal "coisa". É nesta ideia que nos ancoramos para consolidar algo que já estava ali, na nossa frente, preenchido de sentidos de vida, histórias e memórias de cada um dos meninos. Faltava alguma "coisa" para tornar realidade tudo isso que víamos, algo concreto em nossas existências. É nesse momento que paramos para pensar sobre como costumamos delimitar espaços, marcar territórios, reconhecer e pertencer a lugares. É através de um nome. Um nome é a forma que encontramos para dizer que tal "coisa" é ela mesma. É por meio de um nome que chegamos a lugares ou reconhecemos pessoas. Assim como é também por meio de nomes que não chegamos a lugares ou pessoas, repelindo-os antes mesmo de conhecêlos. Comumente, isto acontece quando perguntamos para qualquer pessoa se ela conhece o HCTP. Quase todas as vezes - para não sermos exageradas, porque contamos nos dedos as que não foram - precisamos dizer o que significava cada letra daquela sigla: Hospital de Custódia e Tratamento Psiquiátrico de Florianópolis. Víamos caras de desespero, desentendimento, dúvida, descaso. O nome do hospital é um daqueles que repele as pessoas. Mas será que isso acontece por conta do nome ou das pessoas?

Voltamos para casa com estas inquietações. É hora de pensarmos na próxima oficina. Acho que já sabemos por onde começar.

\section{Deriva VII}

O texto de Godoy (2013, p. 209) sempre nos ajuda nos começos ou nos encerramentos, quando o que queremos é aquela ideia força que se refere à cartografia. E ela diz assim,

${ }^{10}$ Referência a uma fala da psicóloga Eliamar Machado que atua no HCTP.

Revista Digital do LAV - Santa Maria - vol. 10, n. 3, p. 17-30 - set./dez. 2017 ISSN 1983 - 7348 http://dx.doi.org/10.5902/1983734830392 
[...] menos que descrever o já visto, ou dar um contorno e uma localização ao já existente, parece haver [na cartografia], primeiro, o impulso de trazer algo novo para o mundo. [...] É nesse sentido que se poderia arriscar dizer que a geografia não morre, mas reconfigura-se nos termos existentes (GODOY, 2013, p. 209).

Deixamos isso acompanhar o que já dissemos e o que ainda está por vir na experimentação com a geografia. Sim, é da força de inventar mundos para si, da força de poder habitar tais mundos, independente dos lugares onde nos encontramos, pois estamos sempre no meio de alguma coisa, situação, instituição... estamos no meio. 0 que fazemos com as forças do mundo que dobramos?

Não tem sido um mês fácil. O tempo não está ajudando. Queremos ir para fora do espaço físico onde as oficinas geralmente são realizadas, o refeitório do hospital, mas a chuva não deixa. Tudo bem. Ainda podemos considerar que está tudo bem! Mesmo com a caixinha de som quebrada, hoje não vai ter música, aquela com melodia e ritmo. Vamos escutar o som oco das palavras. O eco delas dentro de nós.

Colocamos na mesa três livros de poesia e temos, assim, três novos amigos para conversar: Manoel de Barros, Paulo Leminski e Arnaldo Antunes ${ }^{11}$. O novo exercício era: escolher um poema; refletir sobre a escolha; compartilhar a leitura e reflexão com o grupo. Cerca de 30 minutos depois de ter passado o exercício, o Davi - muito empolgado - começa a nossa troca de palavras e interpretações: "Meu quintal é maior que o mundo", foi como ele escolheu começar: pelo título que o livro carregava. Tem livro de poesia que é assim, o título já é digno de reflexão.

As derivas não terminam aqui, pois as oficinas continuam acontecendo, e os relatos destes viajantes outros continuam sendo escritos. Como dissemos no começo do texto, as derivas se propõem a começar algum movimento. Não há planos certos quando se provoca o pensamento do outro.

E era assim, sempre se retomavam poesias, aquelas de uma outra experiência, dadas no solo da Ilha Paraíso do Ciclo e do Vale das Glórias, ou ainda outras poesias de poetas desconhecidos e conhecidos. Surgem então da contemplação de ilhas e vales uma outra questão: "Há alguma terra ainda incapturável?" De qual terra estavam falando, de quais ilhas...? De todas aquelas que temos a possibilidade de engendrar, dadas as forças de

\footnotetext{
${ }^{11}$ Referimo-nos, respectivamente, às obras Meu quintal é maior do que o mundo (2015), Toda poesia (2013), Agora aqui ninguém precisa de si (2015).
}

Revista Digital do LAV - Santa Maria - vol. 10, n. 3, p. 17-30 - set./dez. 2017 ISSN 1983 - 7348 http://dx.doi.org/10.5902/1983734830392 
um trabalho em educação que as torna possível. Sim, (começa a fazer algum sentido, a criar alguma consistência). Apostamos na ideia de que há muita terra incapturável. "Tenho certeza que elas existem, estão escondidas e ninguém sabe delas. Há muitas coisas que os mapas científicos não pegam", dizia-nos um deles. Alcançáramos até ali o poder de pensar desse modo. A Ilha da qual falavam era então Paraíso do Ciclo, era todos os lugares (Vale das Glórias), terras distantes que inventamos para habitá-las, e elas tinham consistência o bastante (forças) para fazer um pensamento irromper à superfície e habitar o grupo. O lugar-ilha, o lugar-vale, o lugar-encontro tinha sua geografia própria.

As ilhas oceânicas trazem ao ar livre um movimento vindo de baixo: "algumas emergem lentamente, outras também desaparecem e retornam sem que haja tempo para anexálas" (DELEUZE, 2006, p. 17). As ilhas oceânicas nos fazem lembrar que há terra sob o mar, e esta terra, por causas e razões próprias, congrega suas forças para romper a superfície.

$$
\text { - vale das Glírias }
$$

Yosé; ma casa de I urismo do Vale das Glórios, as turistas abtem imformaçises sobues lugares que procuram nu vale. Ce casia fira junter dor kio dos Prazeres muma órlea verabe, com mutas flores e Pin hiros-do-Paraná; a cosa em estilo colonial alemão e' prercurada poristas do mundo inteiro, que vem a este lnogar maravilhoro que i o vale das Glórios. C árua rural, wom suas péabros lagens a pomares contar com un hotel fazende ende é revivide um gartose café da mamba, sé laro, abonial. Nor hoté

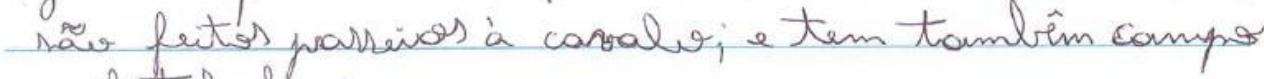
de futebal.

Cino parrad a prefaitiva terminos as caras populares do conjunte abitacional, com Energia heélica e Solor; tem tombèm TV a cabe gratuita pra todo mundo. G cemitério da cidade não í muito groande, porque purca jente morre no Vale dal Glórias.

Figura.04: Relato de um interno do HCTP fruto de uma proposta de escrita de cartas sobre o "Vale das Glórias".

Fonte: Arquivo pessoal.

Revista Digital do LAV - Santa Maria - vol. 10, n. 3, p. 17-30 - set./dez. 2017 ISSN 1983 - 7348 http://dx.doi.org/10.5902/1983734830392 
O território sobre o qual se desenrola nossa deriva é descontínuo no tempo e no espaço, e pode aflorar disperso nos confins de um Hospital, dentro de uma escola, de uma universidade, de um amor... Tais territórios não estão disponíveis e muito menos se encontram prontos às ocupações, são antes invenções. Inventam-se espaços e simultaneamente ocupam-se-os. Espaços que passam a existir nas ocupações (enquanto um jogo dura) e nunca fora, ou antes, delas.

As oficinas são estratégias em educação que servem aos fins que o oficineiro determina em conexão com seu tema de interesse na pesquisa. ${ }^{12}$ Elas foram os operadores deste acontecimento em educação. As derivas fazem a geografia, os geógrafos e seus pesquisadores derivar. Geografias em deriva é um pouco de mar agitado na universidade e em nós, "um pouco do impulso de trazer algo novo para o mundo", e de inaugurar mundos.

\section{Referências}

ANDARILHO. Direção de Cao Guimarães. Minas Gerais: Cinco em Ponto, 2006. (80 min.), $35 \mathrm{~mm}$, color.

BARROS, Manoel de. Meu quintal é maior do que o mundo. Rio de Janeiro : Objetiva, 2015.

Livro das Ignorãças. 3. ed. Rio de Janeiro: Civilização Brasileira, 1994.

LEMINSKI, Paulo. Toda poesia. São Paulo : Companhia das Letras, 2013.

ANTUNES, Arnaldo. Agora aqui ninguém precisa de si. São Paulo: Companhia das Letras, 2015.

CORRÊA, Guilherme. Oficina - novos territórios em educação. In: PEY, Maria Oly. Pedagogia Libertária: experiências hoje. Rio de Janeiro: Imaginário, 2000.

CRARY, Jonathan. 24/7 - Capitalismo tardio e os fins do sono. São Paulo: Cosac Naify, 2014.

DELEUZE, Gilles. A ilha deserta e outros textos. Trad. Coordenada por Luiz B. L. Orlandi. São Paulo: Iluminúras. 2006.

GODOY, Ana. Mìdia, imagens, espaço: Notas sobre uma poética e uma política como dramatizacao geográfica. In: Cazetta, V. e Oliveira Jr. W. (orgs.) Grafias de espaço: imagens da educação geográfica contemporânea. Campinas, SP: Alínea, 2013.

MASSCHELEIN, Jan. E-ducando o Olhar: a necessidade de uma pedagogia pobre. Educação \& Realidade, Porto Alegre, v. 33, n. 1, p. 35-48, jan./jun. 2008.

\footnotetext{
12 Para saber por onde passa a noção de oficina utilizada nesta pesquisa sugiro ver o trabalho de Corrêa (2000).
}

Revista Digital do LAV - Santa Maria - vol. 10, n. 3, p. 17-30 - set./dez. 2017 ISSN 1983 - 7348 http://dx.doi.org/10.5902/1983734830392 
PREVE, Ana Maria Hoepers. Cartografias intensivas: notas para uma educação em geografia. Revista Geografares, Vitória, n. 12, p. 50-75, jul. 2012.

i Acadêmica do curso de Geografia (Licenciatura) na UDESC, bolsista do PIBID/Geografia, membro do Grupo Geografias de Experiência do Laboratório de Estudos e Pesquisas em Geografia/UDESC e da Rede Internacional "Imagens, Geografias e Educação".

ii Professora adjunta no Curso de Geografia e no Programa de Pós-Graduação em Educação na linha de pesquisa Educação e Comunicação da Universidade do Estado de Santa Catarina (UDESC). Membro do Grupo Geografias de Experiência, do Laboratório de Estudos e Pesquisas em Geografia/UDESC e da Rede Internacional "Imagens, Geografias e Educação".

Como citar esse artigo:

BARBOSA, Camila; PREVE, Ana Hoepers. Geografias em deriva. Revista Digital do LAV, Santa Maria: UFSM, v. 10, n. 3, p. 17-30, set./dez. 2017.

Recebido em: 30 novembro 2017

Aprovado em: 06 dezembro 2017 